\title{
On the Role of Functional Categories in Code-Switching: The Igbo-English Examples
}

\author{
Greg Obiamalu* \\ http://dx.doi.org/10.4314/ujah.v14i2.5
}

Abstract

Code-switching (CS) has been defined as 'the act of alternation of two languages within a single discourse, sentence or constituent' Poplack (1980:583). Technically, code-switching refers to alternation between sentences while intra-sentential alternation is referred to as code-mixing. Following Poplack (1980), we use the term code-switching to refer to the intra-sentential alternation which is more amenable to grammatical description. Most scholars on codeswitching will agree that it has a grammar but differ on the nature of this grammar. Some are of the opinion that codeswitching involves two monolingual grammars with constraints that determine points where switches are possible. While some see code-switching as a monolingual grammar where the host or base language provides the mould into which lexical items from both languages could be inserted. The present researcher belongs to the last school of thought. Adopting the Functional Head Selection Constraint of the Matrix Language Frame (MLF) Model proposed by MyersScotton $(1993,1995)$ and with samples of code-switched expression collected from Igbo English bilinguals, the study examines the pattern of code-switching using Igbo and English as the focal point. Igbo is the Matrix language while English is the Embedded language. Our study reveals that the functional heads such as T, Agr, Neg, Det, would normally come from Igbo and provide the skeletal mould. The choice of whether the lexical items will come from Igbo or English or both is determined by the selectional properties of the Igbo functional 
heads. Perhaps this is the case for all other language pairs where one language is the Matrix Language $(M L)$ and the other Embedded Language (EL).

\section{Introduction}

Code-switching is a sociolinguistic phenomenon which is a byproduct of bilingualism. It is a common phenomenon the world over, especially in situations where the participants in discourse share the same bilingual background. In the earlier coinage of the term, there was a distinction between codeswitching and code-mixing. While code-switching refers to alternation in a single discourse between sentences, codemixing refers to alternation within a sentence. In writings on the topic, the two concepts have come to be described with the same term, 'code-switching'. The difference is indicated by the use of the modifying terms, 'intersentential' and 'intrasentential'( Bentahila and Davies 1983, Poplack 1979). The focus of this paper is on the intrasentential code-switching which is the type that is of interest to syntacticians.

Not until recently, intrasentential code-switching was considered to be syntactically random rather than a rulegoverned behaviour' (Pfaff, 1979:294). However, recent studies in different varieties of code-switched languages have shown that code-switching is a rule-governed linguistic behaviour and has certain guiding principles and constraints (cf Pfaff 1979, Kachru 1978, Gumperz 1976, Bentahila and Davies 1983, Poplack 1980, Meechan and Poplack 1995, Myers-Scotton 1993, 1995, Belazi et al 1994, Mcswan 1997). Some of these works attempt to propose some universal principles and constraints on intrasentential code-switching (to be discussed in section 3). Different researchers come up with different constraints which they claim to be universal based on the study of one or more language pairs. Most of these 
proposed constraints have been criticized and rejected or modified as more data come from more language pairs. There seems not yet to be a generally accepted universal constraints on code-switching.

Code-switching is a very common feature of the speech of many Igbo-English bilinguals. Ogbonna (1985) observes that code-switching is more predominant among the Igbo people compared to the other ethnic/linguistic groups in Nigeria. Some writers see this trend from a negative perspective. For example, Ogbonna (1985:5) views codeswitching among the Igbo as 'linguistic sabotage'. According to him,

Unlike the Hausa and the Yoruba, the Igbo man does not discuss in Igbo without adding English words. For example the so-called educated Igbo man speaks thus: Gwa your brother na m choro ihu ya, Gwa Okeke to bring my pen to me, Abiara $m$ so that na anyi ga-eje party

Obiamalu and Mbagwu (2008) adduce some reasons why code-switching is very predominant among Igbo-English bilinguals. The reasons range from language attitude to lexical gaps in the Igbo language.

This paper examines some data on Igbo-English codeswitching (CS) with particular attention on the role of functional categories in the CS expressions. I adopt here the Matrix Language Frame (MLF) model as proposed by MyersScotton (1993, 1995). The major contention of the MLF model is that in every code-switched language pairs, there is a Matrix Language (ML) and an Embedded Language (EL). The ML is the dominant language and provides the skeletal mould and to a large extent determines the grammatical structure of the CS utterances. The ML determines the overall 
morphosyntactic properties of the CS utterances. The ML does all these by providing the functional heads while the EL provides only the lexical categories.. Probably, this is the situation with every language pair where one language is the first language or mother tongue and the other a second language.

The remaining part of this paper is organized as follows. In section 2, we try to show the difference between code-switching and borrowing which are confused in the analysis of code-switching. Section 3 discusses some of the approaches and proposed universal constraints on codeswitching. Section 4 is on the methodology used in eliciting data for the present study. Section 5 dwells on the role of three major functional categories: (C)omplementizer, (I)nflection and (D)eterminer in Igbo-English CS. Section 5 is the summary and conclusion.

\section{Code-Switching or Borrowing?}

Closely related to code-switching is borrowing. Sometimes it is difficult to establish whether the intrusion of a foreign item into a language is an instance of code-switching or borrowing. Pfaff (1979:295) quoting Gumperz and Hermandez-Chavez (1975) speaks of 'code-switching (even that involving the whole sentence) as a type of borrowing'. Code-switching is sometimes distinguished from borrowing using phonological and morphological criteria. Borrowed items are said to be morphologically and phonologically adapted to the host language. Haugen (1956:40) describes borrowing as 'the regular use of material from one language in another language, so there is no longer either switch or overlapping except in a historical sense'. He, however, describes code-switching as a situation 'where a bilingual introduces a completely unassimilated word from another language into his speech'. 
Bentahila and Davies (1983) raise four criteria for distinguishing code-switching from borrowing. We shall examine two of them here. Borrowing could be found in the speech of both monolinguals and bilinguals, whereas codeswitching is only found among bilinguals. This criteria has some problems. Sometimes, elements find their way into another language by borrowing and code-switching and over time become fossilized. They become part and parcel of the speech of both monolingual and bilinguals. Mbagwu (2011:3) notes that "elements that fossilize from borrowing may not be a problem. They may be said to aid development of the L1. The elements that are disturbing are those from code-switching which displace original L1 elements'. In such situations, the monolinguals also use code-switched items and that eventually leads to fossilization of such items and may consequently cause the displacement of the original L1 element. The second point raised in Bentahila and Davies (1983) is that borrowing involves phonological and morphological adaptation of the lexical item into the host language while code-switching does not. However this criterion has been severely criticized. Studies have shown that code-switched elements can undergo phonological and morphological adaptation to fit in properly into the base language (cf Pfaff 1979, Bentahila and Davies 1983, Obiamalu and Mbagwu 2007, 2008). There are many cases of Igbo-English CS where the English word has to undergo some phonological changes to be able to accept the Igbo inflections as shown in (1).

(1) a. $O$ dismantle-go the bed 3S PERF

'He/She has dismantled the bed'

b. Obi stop-uru the cheque PAST 
'Obi stopped the cheque'

The verbs, dismantle and stop may have undergone some phonological modificationsm, especially at the end to enable them accept the Igbo inflections. For example there is an epenthetic vowel after stop which is needed to break the consonant cluster formed by the suffixation of the Igbo past tense marker rụ. The verbs could not be said to be borrowed, they remain English words. They are not part of the Igbo lexicon. The users assume them so. Pfaff (1979:297) suggests that to make a distinction between borrowed items and codeswitched items, the following questions must be asked.

- Does an L1 equivalent exist?

- If so, is it also in use in the community?

- Is the equivalent L1 term known to the individual speakers?

- Does the individual regard the word as belonging to L1 or L2?

Answers to these questions are helpful in determining whether one is dealing with borrowing or code-switching. Based on these questions, we can classify (2) and (3) as instances of borrowing while (4) and (5) are instances of codeswitching.

(2) Table ${ }^{1}$ ahu buru ibu table that be bigness 'That table is big'

(3) $O$ mark-go ule ahu 3S mark-PERF exam that 'He/She has marked the exam'

1 These borrowed words are normally fully adapted to the Igbo phonology. For example, the word 'table' is pronounced 'tebulu', breaking the 'bl' consonant cluster and eliminating consonant in the word final position 
(4)
Mungo Park discover- $a \quad$ River Niger
Mungo Park discover-PAST R. Niger
'Mungo Park discovered the River Niger'

(5) The teacher na-adi very critical

DUR-be

'The teacher is always very critical'

While the words table and mark have been integrated, indigenized and have become part of the Igbo lexicon, it is not so with discover and the phrases the teacher and very critical in (4) and (5) respectively. (4) and (5) provide pure cases of code-switching. (4) provides a good illustration of the role of functional categories in code-switching. The presence of the Igbo past tense morpheme attached to the English verb makes the whole structure to be Igbo, even when all the lexical items are in English.

\section{Constraints on the Syntax of Code-Switching}

Most researchers whose interests are on the structure and syntax of code-switching agree that it is a rule-governed linguistic behaviour and so has a grammar ( Pfaff 1979, Kachru 1978, Gumperz 1976, Bentahila and Davies 1983, Poplack 1980, Meechan and Poplack 1995, Myers-Scotton 1993, 1995). A number of rules and constraints have been proposed. Some of the constraints are specific to certain language pairs, while some are said to be universal. Most of the claimed universal constraints have been criticized, rejected or modified. We shall discuss the Matrix Language Frame (MLF) Model proposed by Myers-Scotton (1993, 1995). The Functional Head Selection Constraint which the present paper adopts is an offshoot of the MLF model. 


\section{The Matrix Language Frame (MLF) Model}

The MLF model was developed by Myers-Scotton (1993, 1995). The thrust of this model is the observation that in every CS language pair, the distribution of the two languages is asymmetrical. One language dominates the other. The dominant language is called the matrix language (ML) and the other one is called the embedded language (EL). The ML might be the first language of the speaker or the language which is more frequently used in speech. Sometimes, it is difficult to define CS structures based on proficiency. When a speaker is proficient enough to make a sufficient grammatical structure in the ML, it is called classical code-switching. It is also possible that some 'speakers do not have full access to the grammatical frame of the intended ML, part of the abstract structure comes from one variety and part from another' (Myers-Scotton and Jake 2002:2). This type of CS is known as composite CS. The Igbo-English CS which this paper intends to investigate is the classical type used by fluent speakers of Igbo whose first language is Igbo and the second, English.

The assumption of the model is that the ML provides most of the words, especially functional words/morphemes, while the EL contributes few lexical items that must fit in properly into the appropriate slots in the sentence structure. Chan (1998:2) notes that in a more up-to-date version of the MLF model (Myers-Scotton and Jake 1995, Jake and Myers-Scotton 1997), it is proposed that an EL word (or more abstractly the lemma ${ }^{2}$ of this EL word) has to be congruent with its ML equivalent for it to be inserted into the code-switched sentence.

\footnotetext{
${ }^{2}$ Lemma is defined as the morphological and syntactic properties which a word inherently posseses. These properties determine its co-occurrence and selectional restrictions. The word is borrowed from Levelt's (1989) model of speech production.
} 


\section{The Lemma Congruence Model}

The Lemma Congruence (LC) model is a sub-model of the MLF. The LC model states that an EL word can appear in code-switching if its syntactic and morphological properties are the same with the ML equivalent. For example, it is only when there is such congruence that an ML head word can select an EL word as its complement.

Myers-Scotton (1993) states two principles underlining the LC model

\section{The Morpheme Order Principle (Myers-Scotton 1993:83)}

In ML+EL constituents consisting of singly-occuring EL lexemes and any number of ML morphemes, surface morpheme order (reflecting syntactic relations) will be that of ML

(6) is saying that in a CS structure, there are more ML morphemes than EL morphemes and that morpheme order is determined by the ML. This principle does not apply in IgboEnglish CS, Let us examine (7) below.

(7) Peter prepare-ra for this exam very well

\section{PAST}

'Peter prepared for this exam very well'

In (7), there is only one morpheme -ra from Igbo, yet Igbo could still be said to be the matrix language in the expression in (7). This is an indication that some other considerations, not number of morpheme, determine the ML and EL distinction. We shall discuss this in more details in section 3.1.2 The second principle of the LC model is as in (8).

\section{The System Morpheme Principle (Myers-Scotton 1993:83)}

In ML+EL constituents, all system morphemes which 
Have grammatical relations external to their head constituent (i.e. which participate in sentence's thematic role grid) will come from the ML

The system morphemes are simply most grammatical functional morphemes as oppose to content morphemes such as nouns verbs, adjectives, etc. What the principle is saying is that functional morphemes such as determiners, conjunctions, quantifiers, modals would normally come from the ML. This leads us to another approach known as Functional Head approach.

\section{The Functional Head Approach}

The major thrust of this approach is that functional categories select specific complements with particular syntactic properties. In addition, these complements must be in the same language with the functional head. This is stated in form of a constraint by Belazi, Rubin and Toribio (1994: 228).

\section{The Functional Head Constraint}

The language feature of the complement f-selected by a functional head, like all other relevant features, must match the corresponding feature of the functional head

The assumption of this constraint is that code-switching does not take place between functional heads and their complements. Just like in a monolingual grammar, there is a close relationship between a functional head and its complement that will not allow the two to come from different languages. This constraint was based on the study of SpanishEnglish by Belazi et al (1994). The constraint has been 
seriously challenged by data from many more language pairs. Manhootian and Santorini (1996) provide so many examples from different language pairs that violate the functional head constraint. There are many language pairs where, for example, the complementizer and its IP complement are not in the same language as shown in (10).

(10) I seen everything [CP 'cause [IP no cogi na]] because not took nothing 'I saw everything because I didn't take anything'

(Spanish-English, adapted from Sankoff and Poplack 1981:6)

There are instances of switches between other functional categories and their complements. Manhootian and Santorini (1996) quoted examples from other sources where there are switches between I and VP (11), D and NP (12) and Q and NP (13).

(11) No parce que [I hanno] [vP donné des cours] no because have given of the lectures

'No, because they gave lectures'

(Italian-French, taken from Di Sciullo, Muysken and Singh 1986:15)

(12) $E$ wo [NP green dress] [D ko] He/She PAST TONE wear green dress ART 'She wore a green dress'

(Adayme-English, taken from Nartey 1982:187)

(13) I'll take [Q some [NP naemaek]

I'll take some salt

'I'll take some salt' 
(English-Farsi, from Mahootian and Santorini 1996:466)

There are instances of the violation of the constraint in IgboEnglish CS as shown in (14) and (15).

(14) Obi ma [CP $n a$ [IP the man is a rogue]] Obi know $\mathrm{C}$ the man is a rogue 'Obi knows that the man is rogue'

(15) The man [I $e$ - [vP disgrace-go himself $]]^{3}$ The man I- disgrace-PERF himself 'The man has disgraced himself'

(14) is an example of switching from Igbo complementizer na to an English IP, the man is a rogue. In (15), there is a switch from Igbo I to English VP, disgrace himself. The form in 24 violates the Free Morpheme constraint which states that a bound morpheme in one language cannot be attached to a free morpheme in another language. It is also a violation of the functional head constraint. From the data shown from (10) to (15), it is obvious that the functional head constraint is not a universal constraint. This led Chan (1998) to modify the constraint as the Functional Head Selection constraint.

\section{The Functional Head Selection Constraint}

Chan (1998:8) states the functional Head Selection constraint as follows:

\section{(16) The Functional Head Selection constraint}

\footnotetext{
${ }^{3}$ The inflectional morpheme that marks perfective Aspect appear in form of a split morpheme which attaches at the beginning and at the end of the English verb, 'disgrace'. This is a violation of the Free Morpheme Constraint (Poplack 1979)
} 
When code-switching takes place between a functional head and its complement, the c-selection requirements that functional heads impose on their complements still holds cross-linguistically

(16) implies that switches can occur between functional heads and their complements as long as the complement observes cselection requirement of the functional head. Chan (1998:9) summarizes the requirements of the functional head selection constraint in the following words:

Under the present approach, a functional head 'f-selects' its lexical complement (i.e. a morpheme/chunk of morphemes) from another language, by entering into a configuration with this complement. The two parts are joined directly by some general syntactic rule (say Merge in the Minimalist framework). The only requirement being that the c-selection requirements of a functional head are fully satisfied. There is no filter of the sort found in the Lemma Congruence Model where EL morphemes are compared with their ML counterparts. Nor are there further mechanisms which lead to the compromise strategy when an EL morpheme is not congruent

We shall adopt the functional Head selection constraint of the MLF model in the rest of our analysis

\section{Methodology}

There were two methods used to collect data for this study. The first method was to draw data from corpus of naturallyoccuring speech of Igbo-English bilinguals. The conversations 
of friends and acquintances in a University campus who are bilingual in Igbo and English were recorded at casual settings where we believe the use of code-swithing is more predominant. The choice of this group of informants is informed by the fact that they are perfect or near perfect bilinguals with good command of both languages. This method has some limitations. For example, it might be difficult to find the particular instances of the kind of switch pattern we are looking out for in the large corpus of recorded conversations. Their non-occurence may not be due to their grammatical deviance but due to lack of motivation to use such structures. This is the reason why we have to supplement our data with the second method which is the acceptability judgement. Specific examples of structures involving a switch are submitted to some of the Igbo-English bilinguals who are requested to judge their acceptability. The same structures were presented to twenty of them. The structures that were judged by all to be unacceptable are marked with the asteriks (*) while those with disagreements on their acceptability are marked with the question mark (?).

In our presentation of data for analysis, the part of the structure that are in Igbo are typed with italics, while the English parts are typed with the normal character

\section{Functional Categories in Igbo-English Code-Switching}

We shall in this section, look at three major functional categories: C(omplementizer), I(nflection) and D(eterminer) and their roles in Igbo-English CS.

\section{The functional category $\mathbf{C}$}

The largest syntactic projection is the Complementizer Phrase (CP). The functional head $\mathrm{C}$ takes a sentence (IP) as its 
complement. Using the $\mathrm{x}$-bar schema, the relationship between the $C$ and the IP is shown in (17).

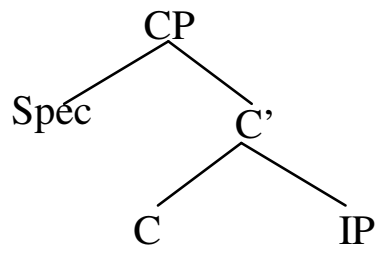

Complementizers are traditionally referred to as 'clause introducers'. Languages have different types of clause introducers. For example, English has different types of complementizers that introduce different types of clauses. The most common ones are: that, if and for. They perform different types of functions by introducing different types of clauses. For example, that is used to introduce a finite declarative clause, if is used to introduce finite interrogative clause, while for is used to introduce non-finite irrealis clause. These are exemplified in (18).

(18) a. John knows [CP that [IP Peter will come]]

b. John wants to know [CP if [IP Peter will come]]

c. John is anxious [CP for [IP Peter to come]]

Igbo has some set of complementizers that perform different functions. Uwalaka (1997) identifies four complementizers in Igbo: ka, ma, na and si. These complementizers introduce different types of embedded clauses in Igbo. Most of them introduce more than one type of clause. For that reason, Uwalaka (1997: 8) notes that 'since the same complementizer can be associated with more than one clause type, it seems inaccurate to claim that complementizers define clause types in Igbo'. 
I present below instances of Igbo-English CS involving complementizers. The CPs are in square brackets.

(19) a. Obi gwara ha [ that we do not need them]

Obi told them

'Obi told them that we do not need them'

b. $O$ na-aju [ whether you will come]

He is asking

'He is asking whether you will come'

c. I told them [ na anyi acho-ghi nsogbu]

$\mathrm{C}$ we want-NEG trouble

'I told them that we do not want trouble'

d. He wanted to know [ ma $i \quad$ ga-ekwu eziokwu]

$C$ you will say truth

'He wanted to know whether you will say the truth'

In (19) a \& b, the matrix clauses are in Igbo, while the embedded CPs are in English. In (19) c \& d, the matrix clauses are in English, while the embedded CPs are in Igbo. These forms of CS do not present difficulty in analysis because the complementisers and their IP complements are in the same language. Let us then, examine (20) to (22), where the complementizers and the IP complements are in different languages.

(20) a. ?Obi gwara $m$ [that $o$ cho-ghi nsogbu] Obi told me $\mathrm{C}$ he want-NEG trouble

b. Obi gwara $m$ [that na o cho-ghi nsogbu] Obi told me C C he want-NEG trouble 
'Obi told me that he does not want trouble'

c. Obi gwara $m$ [na the man does not want trouble] Obi told me $\mathrm{C}$

'Obi told me that the man does not want trouble'

(21) a. Ha ma [na the man is very stubborn] They know C

'They know that the man is very stubborn'

b. ?Ha ma [that nwoke ahu ana-ghi ekwe ekwe] They know $\mathrm{C}$ man that AV-NEG agree agreement 'They know that the man is very stubborn'

c. They know [that na nwoke ahu ana-ghi ekwe ekwe] $\mathrm{CC}$ man that AV-NEG agree agreement 'They know that the man is very stubborn'

a. ?O choro i-ma [whether $i$ ga-abia] he want to-know you will come 'He wants to know whether you will come'

b. O chorọ $\underline{i}$-ma [whether ma $\underline{i}$ ga-abịa] he want to know $\quad \mathrm{C}$ you will come 'He wants to know whether you will come'

The expressions above were submitted to some respondents for acceptability judgment and the results present some interesting insights about Igbo-English CS. (20)a, (21)b and (22)a are judged as unusual and odd. These are cases where the complementizers are in English and the IP complements in Igbo. This is the prediction of the Functional Head constraint (Belazi et al 1994). But (20)c and (21)a, have their complementizer in Igbo followed by IP complement in 
English, yet they are adjudged to be acceptable. In (20)b, (21)c and (22)b, there are two complementizers, one from English and another one from Igbo, yet the structures are adjudged to be acceptable.

The implication of these acceptability judgments is that in Igbo-English $\mathrm{CS}$, the Igbo $\mathrm{C}$ has dominance over the English C. The Igbo $\mathrm{C}$ could license both Igbo and English IP complements as long as the Igbo English IP satisfies the crequirements of the Igbo $\mathrm{C}$. The reverse is not the case, the English $\mathrm{C}$ head does not license an Igbo IP complement. The most interesting observation is the occurrence of double $\mathrm{C}$ which is a violation of the 'doubly filled comp filter'. However, the structures are acceptable, possibly because Igbo allows a sequence of two complementizers. Uwalaka (1997:4) cites some of these examples

(23) a. Ogu hurụ sị na oge agaala

Ogu saw C C time passed

'Ogu discovered that time has past'

b. Obi bịara sị ka ya jụ ya ajuju Obi came $\mathrm{C} \mathrm{C}$ he ask him question 'Obi came to ask him some questions'

$S i$ is an all-purpose complementizer in some dialects of Igbo especially the central dialects. It can be used to introduce any type of clause, alone or with another complementizer. The fact that Igbo could allow two complemntizers, explains why IgboEnglish CS could also accommodate two complementizers. The use of English Complementizer followed by Igbo IP

\footnotetext{
${ }^{4}$ The doubly filled Comp filter has been reject on the understanding that there is a spec position within the $\mathrm{CP}$ projection
} 
complement triggers the introduction of another complementizer from Igbo to license the Igbo IP complement. Observe that the reversal of the order of the complementizers is still unacceptable.

(24) a. *O gwara ha na that anyi acho-ghi nsogbu He told them C C we want-NEG trouble

b. *O choro $i$-ma $\quad m a$ whether $i \quad g a-a b i a$ He want to-know C C you will come

c. *O gwara ha na that the man is very stubborn He told them C C

While (24)a \& b could be said to be ungrammatical because the English $\mathrm{C}$ is closer to the Igbo IP complement and so could not be licensed, the same thing could not be said about the ungrammaticality of (24)c. In (24)c, the English C is closer to the English IP complement, but such a structure makes the CP English and English CP unlike Igbo does not allow a sequence of two complementizers.

The role of the complementizer goes on to support our position that in Igbo-English CS, Igbo is the ML while English is the EL. The Igbo C determines the complement that will follow not minding the language in which it is rendered.

\section{The Functional Category I}

The functional category I which is sometimes abbreviated as INFL stands for Inflection. Inflection is a cover term for grammatical categories found in the sentence structure and most times, associated with the verb in many languages. It includes categories such as auxiliary verb, tense, aspect, mood, voice, sentence negation, agreement, etc. In the recent 
syntactic frameworks, especially the Minimalist program, each of these inflectional categories is assumed to have a separate functional projection, hence: TP, AgrP, AspP NegP, etc. English inflectional categories occur mostly as auxillary verbs, modals and verbal suffixes: -ed, -ing, -en. In Igbo most of the categories are realized as verbal suffixes, while few are realized with the auxiliary forms ga and na.

Due to the affixal nature of some of the inflectional functional categories, their occurrence in Igbo-English CS seems to violate the Free Morpheme Constraint (Meechan and Poplack 1995). It is possible to have CS structures where the Inflectional categories come from Igbo and the verbal base from English. This is shown in (25).

(25) a. Okeke destroyi-ri the evidence

\section{PST}

'Okeke destroyed the evidence'

b. Ike disorganize-ri the queue

\section{PST}

'Ike disorganized the queue'

c. Fela na-ecritisize every government HAB-Pref

'Fela criticizes every government'

d. Emeka $e$-realise-ghi the gravity of the offence Pref- -NEG

'Emeka did not realize the gravity of the offence'

(25) (a-d) are few out of many instances of switches involving English verbs and Igbo inflectional categories. These are clear cases of violation of the Free Morpheme constraint which 
Poplack proposed in her earlier work (Poplack 1980 and again emphasized in her later work (Meechan and Poplack 1995). Some might argue that 25 are cases of borrowing (see section 1 for discussion of the differences between code-switching and borrowing). The English verbs with the Igbo inflections are not viewed nor conceived as borrowed items into Igbo by the Igbo-English bilinguals who use them in code-switching situation. There might be some phonological modification of the English words but it is only at the periphery (morpheme boundaries). This is normally done to accommodate the attachment of the Igbo bound morphemes to the English verb roots. Otherwise, the verb remains unassimilated to the Igbo phonology. Secondly, in most cases, where the English verbs are used, there are readily available Igbo equivalents and so it could not be argued that those forms are borrowed to fill up lexical gaps. Thirdly, the verbs appear with their English morphological structure For example, (25)b has dis-organise which does not follow Igbo morphologically structure. Such a word could not have been borrowed into Igbo. Fourthly, these verbs do not occur in the speech of Igbo monolinguals. For these reasons, we conclude that (25) are not cases of borrowing but code-switching.

It is interesting to note the pattern of switch in the IgboEnglish CS. While it is possible to have English verbs taking Igbo inflections, the reverse is not the case. The structures in (26) are unacceptable

a. *Okeke mebi-ed ugboala ahu Okeke destroy-PST vehicle that Intended meaning: 'Okeke destroyed the vehicle' 
b. *Fela is kocha goomenti obula Fela criticize government every Intended meaning: 'Fela is criticizing every government'

c. *Amaka did not mata ihe o mere Amaka know thing she did Intended meaning: 'Amaka did not know what she did'

The unacceptability of (26) is simply explained because the I category is from English while its complement VP is from Igbo. What does this imply? It again shows that Igbo is the ML and it seems that in code-switched grammar, the functional heads always come from the ML.

It is also interesting to note that the functional category I also determine the type of pronoun that will occur in its specifier position . That is, the subject position of the sentence. If $\mathrm{I}$ is in Igbo (in which it is always in CS situation), then the pronoun ${ }^{5}$ in the subject position must also be in Igbo. This could explain why (27)a is acceptable while (27)b is not.

(27) a. $O$ na-ecriticise every policy of the government He HAB-Pref

He/She criticizes every policy of the government'

b. *He na-ecriticise every government policy.

HAB-Pref

${ }^{5}$ Pronouns are also functional categories. They belong to the class of determiners. 
It seems that the presence of one functional category within a structure demands that the other functional categories must be in the same language. Observe that the Object pronoun within the VP must also be in Igbo if the I is in Igbo, irrespective of the fact that the verb might be in English. This could explain why 28 a $\&$ b are ungrammatical

a. *The man $e$-destroy-go it

Pref- -PERF

Intended meaning: 'The man has destroyed it'

b. *Obi gwara them okwu ojoo

Obi told talk bad

Intended meaning: 'Obi insulted them'

In these examples, there are occurrences of English functional categories, especially the determiner, but such examples as 'the evidence', 'the queue', 'every government' are maximal projections of the DP category and therefore islands not affected by the functional head selection constraint of CS grammar.

\section{The Functional Category D}

The category traditionally referred to as NP has come to be known as DP (Abney 1987). The argument is that it is the determiner rather the noun that actually heads a nominal argument phrase. The determiner is to the nominal phrase, what inflection is to the sentence. Determiners belong to the class of functional categories capable of projecting their own maximal project, hence DP. The arguments for or against the DP analysis is outside the scope of this paper. What is of interest is the behaviour of elements assumed to be determiners in Igbo-English code-switching. 
In English, the class of items normally designated as determiners include: articles, demonstratives, quantifiers and numerals. These are called prenominal modifiers. The pronoun has also been classified as a determiner and referred to as pronominal determiner (Radford 2004:44).

In Igbo, on the other hand, there is no equivalent of articles in English. However there are some group of postmodifying elements such as demonstratives and quantifiers. It is still not agreed whether they are determiners or different kind of functional categories: Demonstrative Phrase (DP), Quantifier Phrase (QP). For the purpose of this paper, we shall assume them to be determiners. It is important to note the variation in word order in English and Igbo nominal phrase. In English, the determiner comes before the noun while in Igbo, determiner comes after the noun as shown in (29) and (30)
(29) a. the man
b. those Chairs
c. three houses
(30)
a. nwoke ahu
man that
'that man'
b. oche abuo
chair two
c. ulo niile
'two chairs' house all 'all the houses'

Also note that English nouns take plural inflection while Igbo nouns remain bare when plurality is implied. Below are collected instances of switching within the nominal phrase.

a. [DP Priest abuo ahu] bu friends

Priest two $\mathrm{D}$ be friends

'The two priests are friends'

b. [DP Batch obula] nwere number batch every own number 
'Every batch has a number'

c. [DP Comportment ya] dị egwu

PGEN be fear

'His/Her comportment is wonderful'

In (31), the functional words, abụọ, ahụ, ọbụla and ya are in Igbo, while the nouns are in English. Notice that the presence of the Igbo functional words cause the English noun priest in (31)a to occur uninflected for plural. A situation where the functional words are in English and the lexical nouns are in Igbo are not found in corpus of Igbo-English CS. They are adjudged to be odd by most of our respondents.(32) are odd structures going by the acceptability judgement.

a. ?The nwoke man b. ?Every ulo

house c. ?all osisi tree

32 shows that English determiners cannot come before Igbo nouns, but this should be expected since the order for Igbo which is the ML is Noun Determiner. For that reason, you would not find any expression such as 'nwoke the' or 'ụlọ every'. We observed that contrary to our data in (32), when a noun with generic reference such as 'man', 'boy', 'people', is used, it does not accept Igbo functional modifiers. This explains the oddity of (33).
a. *man ahu man that
b. *people niile
c. *boy $a$ 'that man' people all boy this 'all the people' 'this boy'

The explanation for the ungrammaticality of (33) is that the generic English nouns are marked for genericity by a null 
determiner. In other words, they go beyond just lexical noun but a noun with an implied functional element which applies only in English and so will not permit a functional element from Igbo as its modifiers. In other words, such English nouns do not satisfy the c(omplement)- requirements of the Igbo determiners.

The acceptability of (31) and the unacceptability of (33) again confirm our position that Igbo is the ML while English the EL in Igbo-English CS. The ML contributes the functional categories while the EL contributes only lexical categories. In Igbo-English CS, the functional heads always come from Igbo (except when the English expression within the CS is a maximal projection of its own. In that case it is an 'island' (Jake and Myers-Scotton 1997)). The Igbo functional heads select the appropriate complement which may come from any of the two languages as long as the complement-type requirement of the Igbo functional head is met. This is in line with Functional Head Selection approach proposed by Chan (1998) after studying data from Cantonese-English CS (two languages that are very different in structure).

\section{Summary and Conclusion}

In this paper, I have looked at the role of functional categories in code-switching using Igbo-English as a reference point. The paper started with making a distinction between codeswitching and borrowing, showing that any use of an L2 item where there is a readily available L1 equivalent is a case of code-switching. The paper set out to establish that the matrix language frame model for analysis of code-switched grammar is valid. Igbo is the ML while English is the EL. Igbo is the ML, not because it has more morphemes than English in the CS structure but because it provides the functional categories 
which determine whether English complement could follow or not.

Within the $\mathrm{CP}$, the $\mathrm{C}$ head must be in Igbo while the IP complement could come from English or Igbo. The reverse is not the case since the English $\mathrm{C}$ cannot take the Igbo IP complement. The presence of an English $\mathrm{C}$ requires an additional $\mathrm{C}$ from Igbo giving rise to a double $\mathrm{C}$ construction.

We also observed that while it is possible to have English verbs taking Igbo inflections, Igbo verbs do not take English inflections. This implies that the functional head I must be in Igbo while the VP can be in English.

Within the nominal phrase, we also observed that Igbo determiners readily go with English nouns, whereas English determiners are hardly found with Igbo noun. The only exception is when the English noun has a generic reference. In that case, it requires a determiner that is also from English.

The overall implication of our results is that the functional head determines the dichotomy between ML and EL in code-switching. The ML provides the functional heads which determines the kind of complement that will follow. The complement could come from any of the two languages provided the necessary features are present. In other words, any of the two languages could come in provided that the $\mathrm{C}$ selection requirements of the functional head are met.

Greg Obiamalu is of the Department of Linguistics, Nnamdi Azikiwe University, Awka. 


\section{References}

Abney, Steven. 1987. The noun phrase and its sentential

aspect. Cambridge MA: MIT dissertation

Belazi, Hedi, Edward Rubin and Jacqueline Taribio. 1994. Code-switching and x-bar theory: the functional head constraint. Linguistic Inquiry 25. $221-237$

Bentahila, Abdelâli and Eirlys Davies. 1983. The syntax of

Arabic-French code-switching. Lingua 59. $301-330$.

Chan, Brian. 1998. Functional heads, Cantonese phrase structure and Cantonese-English code-switching. UCL working papers in Linguistics 10. http://www.phon.ucl.ac.uk/home/PUB/WPL/98papers/ chan.pdf

Gumperz, John. 1976. The sociolinguistic significance of conversational code-switching. In Papers on language and context, ed. by Jenny Cook-Gumperz and John Grumperz, Working Paper 46, Berkeley: University of California

Gumperz, John and Eduardo Hermandez-Chevez. 1970. Cognitive aspects of bilingual communication. El lenguaje de los chicanos, ed. by Eduardo HermandesChevez. Arlington: Centre for Applied Linguistics

Haugen Einar. 1973. Bilingualism, language contact, and immigrant languages in the United States: A research report, 1956 - 2970. Current trends in Linguistics, ed. by Thomas Sebeok 10. $505-591$. The Hague: Mouton

Jake, Janice and Carol Myers-Scotton. 1997. Code-switching and compromise strategies: implications for lexical 
structure. International Journal of Bilingualism 1(1). 25 $-40$

Kachru, Braj. 1978. Towards restructuring code-switching:

The Indian perspective. IJSL 16, 27-46

Manhootian, Shahrzad and Beatrice Santorini. 1996. Codeswitching and the complement/adjustment distinction. Linguistic Inquiry 27,3,464 - 479

Macswan, Jeff. 1997. A minimalist approach to intrasentential code-awitching: Spanish-Nahuati bilingualian in Central Mexico. University of California, Los Angeles $\mathrm{Ph}$. D dissertation.

Mbagwu, Davidson U. 2011. The fossilization of foreign lexical items in Igbo: an imperative for a lexical documentation in the language. A paper presented at the Faculty of Arts conference, Nnamdi Azikiwe University Awka. May 4 - 72011

Meechan Marjory and Shana Poplack. 1995. Orphan categories in bilingual discourse: Adjectivisation strategies in Wolof-French and Fongbe-French bilingual discourse. Language Variation and Change 7 (2), 169-94

Myers-Scotton, Carol. 1993. Duelling languages: grammatical structure in code-switching. Oxford: Oxford University Press

Myers-Scotton, Carol. 1995. A lexically-based production model in code-switching. In One speaker, two languages: cross disciplinary perspective on codeswitching, ed. by Lesley Milroy and Pieter Muysken, 233-256. Cambridge: Cambridge University Press.

Myers-Scotton, Carol and Janice Jake. 1995. Matching Lemmas in a bilingual language competence and production model: evidence from intrasentential codeswitching. Linguistics 33, 981 - 1024. 
Obiamalu, Greg and Davidson Mbagwu 2008. Motivations for Code-switching among Igbo English Bilinguals: A Linguistic and Socio-psychological survey in OGIRISI : A New Journal of African Studies Vol 5, 2008.

Ogbonna, Chris. 1985. Immortalizing Igbo Language. Nigerian Statesman: a Nigerian dailies Tuesday Jan 8: p 5

Pfaff, Carol. 1979. Constraints on language mixing: intrasentential code-switching and borrowing in Spanish/ English. Language 55, 2, 291 - 318

Poplack, Shana. 1980. Sometimes I'll start a sentence in Spanish Y TERMINO EN ESPANOL: toward a typology of code-switching. Linguistics 18, 581 - 618

Radford, Andrew. 2004. The minimalist program and the structure of English. Cambridge: Cambridge University Press

Uwalaka, Mary-Angela. 1997. The functional category comp in Igbo. Humanities Research monograph. University of Ibadan. 